\title{
CAMPO EXPANDIDO EM ABORDAGENS DO LITERÁRIO ${ }^{1}$
}

\section{EXPANDED FIELD IN LITERARY APPROACHES}

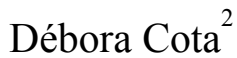

\begin{abstract}
RESUMO: O conceito de campo expandido, como o propõe Rosalind Krauss (1979), está sendo considerado dentro dos estudos em torno da literatura a partir de trabalhos, sobretudo contemporâneos, de experimentação com a escrita. A discussão em torno da pós-autonomia do literário (LUDMER) ou de sua inespecificidade (GARRAMUÑO), em diálogo estreito com a ideia de ampliação do campo, no entanto, considera também mudanças em torno da leitura do literário, de sua abordagem. De que maneira leituras que constroem um objeto ao ler promovendo um extravasamento do campo pelas associações e comparações com outros campos e/ou outros objetos, como o trabalho de Raúl Antelo em Paraná (2017), estabelecem leituras do literário em perspectiva expandida? Este trabalho, aberto muito mais a interrogações do que a respostas, propõe uma discussão do campo expandido a partir, especialmente, da leitura do literário e suas interlocuções com às práticas do comparatismo.
\end{abstract}

PALAVRAS-CHAVE: campo expandido; leituras do literário; literatura comparada.

ABSTRACT: The concept of expanded field, as proposed by Rosalind Krauss (1979), is being considered within the studies around the literature from works, especially contemporary, of experimentation with writing. The discussion about the post-autonomy of the literary (LUDMER) or its nonspecificity (GARRAMUÑO), in close dialogue with the idea of broadening the field, however, also considers changes around the reading of the literary, its approach. How do readings that build an object when reading promoting an extravasation of the field by associations and comparisons with other fields and / or other objects, such as the work of Ana Pizarro (2012), Amazonia: the voices of the river or Paraná, by Raúl Antelo (2017), establish readings of the literary in expanded perspective? This work, much more opened to questions rather than answers, proposes, especially, a discussion of the expanded field from reading of the literary and its interlocutions with the practices of comparatism.

KEYWORDS: expanded field; literary readings; comparative literature.

\footnotetext{
${ }^{1}$ Uma versão deste texto foi apresentada no GT de Literatura Comparada, durante o XXXIII ENANPOLL, realizado entre 27 e 29 de junho de 2018, em Cuiabá (MT).

${ }^{2}$ Doutora em Literatura (2010), pela Universidade Federal de Santa Catarina.
} 
Rosalind Krauss escreve o artigo A escultura no campo ampliado, em 1979. A autora não é apenas professora de história da arte moderna e contemporânea na Universidade de Columbia, em Nova Iorque mas, colaboradora e co-fundadora da revista de crítica e teoria de arte contemporânea October. Fundada em 1976, a revista é responsável pela difusão da teoria pós-estruturalista francesa para a língua inglesa. Apesar de continuar pensando a história, o grupo em torno da revista possui uma posição contra o historicismo enquanto evolução contínua e referência sobre a qual se instaura o modernismo e a ideia do novo. Rosalind Krauss diz claramente no texto, em tom crítico: “O novo é mais fácil de ser entendido quando visto como uma evolução de formas do passado.” (KRAUSS, p. 129) Neste sentido, visavam, dentro de uma perspectiva pós-estruturalista a problematização de categorias bases, criando outra possibilidade de narração em torno das mudanças na arte.

Esta será, de algum modo, a metodologia posta em prática por Kraus ao analisar o movimento sofrido pela categoria "escultura" na história da arte. Primeiramente, a escultura tem na localização um elemento primordial para sua definição. Possui uma função monumental, desde os gregos e antigos romanos até, especialmente, a produção europeia do século XIX. Os pedestais são de suma importância, segundo a autora, na mediação entre o local onde se situam e o signo que representam. Posteriormente, no modernismo, a escultura autonomiza-se desligando-se do pedestal, ou seja, deixa de ser vista como monumento fixo e com função definida. Assim sendo, acaba por desenvolver certa complexidade na relação que estabelece com dois elementos primordiais, a paisagem e a arquitetura: não há uma inteira identificação com estes elementos. A escultura pensada por este binarismo passa a ser concebida entre a não arquitetura e a não paisagem. Por fim, no que a autora propõe chamar de pós-modernidade, há uma ampliação do campo relativo à escultura. Ao voltar às categorias primordiais que se encontram na base de sua definição, o binarismo arquitetura e paisagem, a autora observa que agora elas não estão apenas presentes em formas negativas como também em forma positiva: a escultura em campo ampliado, portanto, incluiria paisagem e não paisagem, arquitetura e não arquitetura alargando assim suas possibilidades de manifestação.

A ideia de escultura em campo ampliado para Rosalind Krauss estaria, portanto, primeiramente associada a um momento específico, a arte a partir dos anos 60 ou ao pós-modernismo, termo que adota a partir da crítica de outras áreas que lhe é contemporânea. 
Neste período, o que se apresenta como escultura, começa a por em xeque aquilo que se define como escultura. Ou seja, parte-se das próprias esculturas na definição de um alargamento do campo. Propõe-se então uma ampliação do campo a partir da ineficácia de atributos concedidos até então a ele, principalmente, que sustentavam sua autonomia e auto-referencialidade que já não funcionariam mais. Por outro lado, é uma ampliação no sentido de exacerbação, alargamento de um campo anteriormente fechado. Seria uma ampliação do campo no sentido de um esfacelamento da relação que mantinha enquanto campo autônomo com outros campos. Agora, acaba por definir-se também com outros campos e, portanto, parece não manter mais sua autossuficiência.

A literatura, nas últimas décadas, tem recorrentemente discutido seu estatuto e na América Latina sua saída da autonomia é tema de debate em textos como os que falam em "literatura pós-autônoma”, Josefina Ludmer ou "inespecificidade da estética contemporânea", Florencia Garramuño. A primeira proposta, reunida depois do lançamento de textos soltos, em livro intitulado Aqui América Latina, una especulación (2010) parece apoiar-se em método semelhante ao de Kraus: parte-se da literatura latino-americana contemporânea (na qual inclui-se o Brasil), especialmente, a dos anos 90 e início dos anos 2000 (não utiliza como referência temporal o termo pós-modernidade ou pós-modernismo apesar de parecer estar implicitamente contido no conceito de pós-autonomia). Colocam-se em xeque categorias fundamentais sobre as quais está baseada a autonomia do campo literário, quais sejam, o também binômio realidade e ficção. E, por fim, propõe-se um alargamento do campo, mostrando o quanto ele agora se mistura a outros campos, desfazendo o binarismo realidade e ficção no qual se apoiava para se definir. Não se pode esquecer que Josefina Ludmer também foi professora de uma universidade americana na qual a desconstrução tinha um papel relevante: a Universidade de Yale. Mas, sem considerar as questões relativas a cada área nessa comparação, pode-se dizer que há um ponto central que distancia a abordagem das duas ensaístas, a transferência da criação para o modo de leitura, na última. Ludmer põe no centro de atenção, ainda que também valorize as mudanças da própria literatura, a abordagem do literário. Sobre as obras que se detém afirma: “Aparecen como literatura pero no se las puede leer con critérios o categorias literárias como autor, obra, estilo, escritura, texto y sentido. No se las puede leer como literatura porque aplican a la literatura una drástica operación de vaciamiento (...).” (LUDMER, 2010, p. 150) 
Por outro lado, é inegável a distância entre elas pela plasticidade da forma inerente ao objeto escultórico. A ampliação do campo pressupõe mudanças estruturais no objeto artístico. Enquanto na literatura pós-autônoma, ainda que as condições materiais como a ampliação do uso da Internet e as redes colaborativas de produção sejam consideradas, as mudanças não são necessariamente decorrentes das alterações do formato livro. A saída da determinação autonomista do campo se dá, neste caso, pelo papel praticado pelo que é produzido como literatura dentro da vida social, uma "realidadficción". A literatura segue circulando como literatura, segundo Ludmer.

II

Na mesma linha têm se apresentado as discussões de Florencia Garramuño acerca da inespecificidade do literário. No entanto, Garramuño expõe um diálogo direto com as propostas de Rosalind Krauss ao utilizar de seus trabalhos para construir suas considerações em torno da inespecificidade do literário: “(...) a ideia de um campo expansivo - com suas conotações de explosões internas e de constante reformulação e ampliação - talvez seja mais apropriada para refletir sobre uma mutação daquilo que define o literário na literatura contemporânea, que em sua instabilidade e ebulição atenta até contra a própria noção de campo como espaço estático e fechado" (2014, p. 21), afirma a autora. Já o diálogo com Josefina Ludmer ou a ideia de Pós-autonomia do literário não é tão evidente apesar de impossível de ser descartada. Ludmer aparece entre as pessoas a quem Garramuño agradece a inspiração do livro Frutos estranhos (2014) no qual desenvolve a ideia de "inespecificidade do literário" e de "literatura fora de si”. Mas em livro anterior, de 2012, A experiência opaca: literatura e desencanto, no qual Garramuño dedica um capítulo para tratar sobre a "Saída da autonomia", textos de Ludmer sobre a pós-autonomia aparecem na bibliografia. Por outro lado, assim como Rosalind Krauss e Josefina Ludmer, Florencia Garramuño se detém sobre uma produção literária recente, "arte das útlimas décadas" (2014, p.16), esclarece ela em Frutos estranhos. Apesar de em algum momento demonstrar-se contrária a uma periodização. 3

O conceito de inespecificidade é gestado a partir de vários exemplos de produções literárias desde as que contém em si um diálogo direto com outras artes, até as que propõem um desgarramento de elementos fundamentais para uma concepção autonomista da literatura

\footnotetext{
${ }^{3}$ Cf. A literatura fora de si, em Frutos Estranhos, 2014, p. 33.
} 
como o território e a língua. Também não deixa de considerar, a autora, a indistinção entre realidade e ficção, como a que ocorre na obra Desarticulaciones, de Sylvia Moloy. Para ela: "A indistinção entre realidade e ficção lança a especificidade da literatura para uma zona em que as elucubrações sobre ela valem mais pelo que dizem com respeito a questões existenciais ou conflitos sociais que habitam esse outro espaço com o qual se elabora essa contiguidade, do que por aquilo que elas podem dizer a respeito do texto, do texto enquanto tal, em sua especificidade.”(GARRAMUÑO, 2014, p. 22) Contudo, o foco está também no que a literatura examinada propõe e não em seus modos de leitura.

Contudo, seu artigo de 2009, publicado no Brasil na Revista de Estudos Culturais da Universidade Federal do Mato Grosso do Sul, La literatura en un campo expansivo: y la indisciplina del comparatismo propõe não apenas discutir os modos de leitura ao colocar em diálogo o conceito de campo ampliado e a literatura comparada, mas avança nesse sentido através de indagações relevantes:

Conviene plantear desde el comienzo el interés coyuntural de este análisis. El modo en que estos desbordamientos comprometen una definición de lo disciplinario de la literatura, ¿podría servir de inspiración para pensar en nuevas formas contemporáneas del comparatismo? Es claro que si estas literaturas en un campo expansivo conforman el objeto de un estudio comparado, varias de las estrategias que marcaron a los estudios comparados -como el trabajo con las diferentes tradiciones nacionales o la comparación de literaturas concebidas como unidades cerradas en sí mismas, por hablar sólo de los más evidentes- no tendrían mucho sentido ni asidero en textos de este tipo. ¿Cómo debiera, por lo tanto, concebirse un comparatismo que trabajara con tales textos? ¿Cuáles serían las inspiraciones que podríamos deslindar de una literatura en un campo expansivo para pensar el lugar de lo argentino-brasileño en los estudios contemporáneos? ¿Podría además un comparatismo definido a partir de la literatura en un campo expansivo expandirse él mismo también sobre otro tipo de textos e iluminarlos desde esa mirada anacrónica que propugnara Didi Huberman en Ante el tiempo? (GARRAMUÑO, 2009, p. 2-3)

Tais indagações, muito consoantes com a proposta deste estudo, no entanto, não são especificamente o objeto de atenção de Garramuño que, antes de qualquer coisa, pretende voltar-se aos desbordamentos sistemáticos do literário propostos pelos textos contemporâneos. Mas, é com estes desbordamentos, a partir de um poema de Carlito Azevedo que proporá pensar o comparatismo em campo expandido:

En el poema de Carlito, lo argentino brasileño - como en varios otros poemas de Marília Garcia o de Cristian de Nápoli, de Ricardo Domeneck o Cristián 
Aliaga- no refiere ni a tradiciones nacionales, ni a espacios fijos y cerrados ni, tampoco, a trayectorias sociohistóricas semejantes, sino a flujos contingentes de amistades, lecturas y mutuas inspiraciones transnacionales. Lo que haría que, si de estudios comparados se trata, para apresar estas literaturas en un campo expansivo en sus múltiples conexiones no se debería "comparar" dos entidades diferentes en sus semejanzas o diferencias, sino transitar sus flujos, recorrer sus contactos y, sobre todo, proponer conexiones conceptuales entre ellas. (GARRAMUÑO, 2009, p. 7)

Garramuño apresenta aqui uma proposta de abordagem do que seria, a partir da literatura comparada, trabalhar em campo expandido apoiada especialmente no que Kenette Reinhard, professora de Literatura Comparada da Universidade da Califórnia, Los Angeles, propõe como literatura comparada, ou seja, um comparatismo muito mais voltado à "vizinhanças determinadas por contiguidade acidental, isolamento genealógico e encontro ético" (REINHARDT apud GARRAMUÑO 2009, p. 8, trad. minha) do que por comparações, similaridades e diferenças. Trata-se de um posicionamento que incide sobre a forma de abordagem dos objetos e que parece implicar em não reforçar a ideia de objeto como unidade em si mesma ao dizer que são similares ou diferentes mas, como Garramuño afirma acima, fazer transitar os fluxos entre elas, percorrer as formas como entram em contato e indicar, promover "conexões conceituais" que as coloquem em relação.

Florencia Garramuño está pensando a expansão do campo como uma abertura a uma presença, uma fractalidade, conforme Jean Luc Nancy. O que não implica, como se pode observar através dos vários exemplos que explora, necessariamente, em uma mudança no formato do livro ou do gênero ou a existência de referências culturais a serem comparadas. No poema de Carlito Azevedo, intitulado Margens/Márgenes, por exemplo, o que muda, além da invasão literal do que seriam as margens do poema, são as referências e a presença da língua espanhola vistas por Garramuño como "flujos contingentes de amistades, lecturas y mutuas inspiraciones transnacionales" já que não há referências "ni a tradiciones nacionales, ni a espacios fijos y cerrados ni, tampoco, a trayectorias sociohistóricas semejantes". (2009, p.8)

Por outro lado, ainda que não chegue a desenvolver esta questão e que analise em seu texto apenas obras contemporâneas, Garramuño parece também se perguntar sobre a validade da abordagem em campo expandido para além dos textos contemporâneos ao lembrar da perspectiva de Didi Huberman em torno do anacronismo. O anacronismo para Didi Huberman diz respeito a ideia de uma atualidade do passado que, se pensada desde o literário, 
possibilitaria uma abordagem de textos não contemporâneos pelo que eles contêm de atual ou, para dizer de outra forma, de presença do futuro:

\begin{abstract}
¿Podría además un comparatismo definido a partir de la literatura en un campo expansivo expandirse él mismo también sobre otro tipo de textos e iluminarlos desde esa mirada anacrónica que propugnara Didi Huberman en Ante el tiempo? (GARRAMUÑO, 2009, p. 2-3)
\end{abstract}

Considerados estes aspectos, pretende-se a partir de agora pensar o comparatismo na atualidade a partir de um trabalho de leitura que parece aproximar-se a uma abordagem em campo expandido. Raúl Antelo em Paraná (2017) lida com materiais com certa diversidade de proveniência e de época através dos quais se constrói o que seria o Paraná uma vez que não se restringe apenas a referências a lugares mas, organiza, a sua maneira, uma série de ideias relacionadas a ele.

III

O próprio formato livro em Paraná foge ao padrão: são apenas 20 páginas editadas não em forma de ensaio como costumam apresentar textos desse tamanho mas, em forma de livro, acessível através apenas pela solicitação direta à editora que produz um volume único para cada pedido. Rompe-se com o formato e rompe-se com os modos tradicionais de comercialização. Mas, há também um rompimento visível com o literário em sua forma de abordagem: espera-se uma crítica baseada em conteúdos de obras mas o que é apresentado, ainda que não se possa descartar totalmente essa abordagem do conteúdo, é uma leitura que parte especialmente de um dado biográfico a respeito dos autores: "Vou falar de escritores nascidos no Paraná”, (2017, p. 8), afirma Antelo.

Assim, não interessa ao autor diretamente o conteúdo das obras do escritor argentino Eduardo Wilde mas, o fato de que ele foi casado com a irmã do militar Filiberto de Oliveira Cézar y Diana que "não nasceu exatamente à beira do Paraná, mas em Villaguay" (2017, p. 8-9). E ainda que sobre Eduardo Wilde, Borges escreveu uma página na qual exalta o fato de Wilde ter alcançado a veracidade literária a qual ele não gostaria de insinuar que é ficção (2017, p. 9). Ou seja, são armadas na obra uma série de expectativas frustradas, como a de que se comentará apenas a respeito de autores provindos do Paraná, e coordenando esta série 
ou as relações entre elementos díspares na abordagem encontra-se o que o autor denomina de "paranoia Paraná".

Neste sentido, é interessante observar como a "paranoia Paraná" alia as províncias do Paraná brasileira e argentina: o escritor Manuel Gálvez (1882-1962), proveniente do Paraná argentino, escreve uma biografia sobre o líder político Aparicio Saraiva (Vida de Aparicio Saraiva, Buenos Aires: Emecé, 1962), que, apesar de uruguaio, esteve envolvido na Revolução Federalista no Brasil. Sua biografia faz, por exemplo, referência ao cerco da Lapa: episódio histórico da Revolução Federalista ocorrido no estado brasileiro do Paraná. Não são dois autores provindos daquelas províncias que são comparados mas é considerado o fato de um deles escrever sobre um político envolvido em um episódio histórico da outra província (Cf. ANTELO, 2017, p. 14). Ou seja, em muito lembra uma abordagem comparatista como aquela proposta por Garramuño motivada muito mais por avizinhamentos, por fluxos, do que por elementos nacionais fixos. Inclusive coloca-se em questão os dados biográficos, como o lugar de origem, como fontes desde as quais se pode designar, definir uma identidade, uma subjetividade, ainda que sejam delas, das biografias, que partem as associações nem sempre previamente determinadas.

Em uma parte final do livro/ensaio o autor parece explicar seu método: trata-se da busca pela eliminação da rigidez dos objetos, dos "receptáculos das convenções como a que diz que Paraná é apenas um estado do Brasil, e isto supõe questionar a leitura do espaço como a base rígida da nossa existência e como o próprio signo da nossa duração.” (ANTELO, 2017, p. 19) Ainda que este possa ser a construção de um método para a abordagem do literário, aqui não mais encontra-se um entendimento moderno e autonômico do literário. E sim a criação de um espaço no qual, o método de leitura também se vale de um método artístico criativo e no qual crítica e ficção podem ser ambivalentes ou, o que seria nas palavras de Garramuño, um espaço de inespecificidades.

Assim como interessa a Raúl Antelo o sistema de boa vizinhança aplicado por Aby Warburg à história da arte, o método paranoico-crítico do surrealismo de Salvador Dalí e os estudos que fez dele Jacques Lacan estão entre os materiais de pesquisa do crítico argentino/brasileiro. Enquanto Lacan alia a paranoia à cura, Dali a insere em sua estética e a utiliza para ler imagens. As palavras de Briony Fer em torno do "rosto paranoico" do artista nos dão elementos para pensá-la como método de leitura: 
Em 1931, (...) Dali havia produzido seu "rosto paranoico", em que a fotografia de uma aldeia africana, ao ser virada de lado, transformava-se no perfil de um rosto. Isso mostra, novamente, o interesse do Surrealismo pela metáfora, pela ideia de que uma coisa podia simultaneamente ser lida como outra sem nunca perder inteiramente sua identidade original. (1998, p. 220)

As imagens paranoicas ocorrem devido ao delírio de interpretação e podem proliferar-se infinitamente (FER, 1998, p. 221), fato também observado na famosa leitura paranoica que o artista realiza do Angelus de Millet. Dali procura sistematizar ao redor da obra uma série de conteúdos, ora chamados de "delirantes", ora de "fantasias" ou então analogias, por ela desencadeados ${ }^{4}$.

Para o crítico argentino, Daniel Link, autor de Como se lê (2002), há um deslocamento do sentido para algo entre a 'tirania do sujeito' e as “propriedades do objeto" que possibilita a entrada da paranoia na leitura (2002, p. 27). E em resenha sobre Crítica acéfala, livro de Raúl Antelo publicado em Buenos Aires, em 2008, afirma que: “o dispositivo paranoico levanta sua força antidogmática, propondo uma relação entre lugares distantes que não responde nem à escolástica universitária nem tampouco aos processos de abdução, mas a essa potência divinatória do inter (entre a ficção e a teoria).” (2009, p. 227) Link destaca da leitura paranoica de Dali, o foco do sentido no estabelecimento da série. A série é constantemente para onde nos empurra a leitura de Paraná. Há uma serialização constante e desestabilizadora de sentidos dados previamente. O vocábulo Paraná se prolifera a partir da inserção de cada nova biografia de alguma figura que ali nasce e a cada nova associação que informações em torno desta biografia podem suscitar. Desse modo, propõe o foco muito mais no funcionamento do que no lançamento de hipóteses de sentido. Este é, para retornar à discussão em torno da inespecificidade, conforme o Indicionário do contemporâneo (2018, p. 214), um dos traços marcantes das literaturas contemporâneas que justamente demonstram desvirtuações do literário, "práticas inespecíficas": "são mais performáticos do que retóricos", afirma o texto.

Por outro lado, o método paranoico crítico utilizado para a leitura é também um método artístico, de criação, ou seja, a "paranoia Paraná” pressupõe a superposição de técnicas, na qual encontra-se uma técnica de criação artística surrealista, que além de método de leitura é também criação. Tais superposições são, para Garramuño (2014), um modo de questionar a especificidade na estética contemporânea. Assim sendo, caberia perguntar se não

\footnotetext{
${ }^{4}$ Cf. DALÍ, Salvador. El mito trágico del “Angelus” de Millet. Trad. Joan Vinolly. Barcelona: Tusquets, 1978.
} 
é a leitura paranoica, enquanto método artístico empregado para a leitura do literário, mas também enquanto método que leva a ambivalência entre crítica e ficção, um instrumento crítico que estaria atuando em campo expandido. Da mesma forma, em suas leituras, inclusive de obras literárias do passado, não estaria apresentando o campo literário como irredutível e aberto ao colocar em xeque, esvaziar de sentidos prévios elementos marcantes das obras, como no caso o elemento espacial Paraná?

\section{IV}

Assim como Ludmer e Garramuño, Antelo também problematiza em seus trabalhos críticos a autonomia do literário na contemporaneidade e com ela a própria crítica literária. A leitura serial elaborada, as associações múltiplas condicionam uma prática criativa de leitura e, assim, uma deliberada confusão entre crítica e ficção que remontam as discussões articuladas por Antelo em torno da "pós-crítica". Organizador do Colóquio Pós-crítica 6 , Raúl Antelo afirma que a pós-crítica aplica procedimentos modernistas como o de estranhamento e montagem, além de outros provindos das artes plásticas, da antropologia estrutural e da psicanálise lacaniana, em sua prática. "É uma forma de ensaiar a pós-autonomia, em que um valor oscila enquanto neutro" (ANTELO; CAMARGO, 2007, contra-capa), afirma o autor, constatando as implicações decorrentes de tal perspectiva. A pós-crítica, ainda conforme Antelo, não considera a relação autonômica entre autor e leitor mas sim, a "alteridade implícita em todo ato crítico", alteridade esta definida por aquilo que ainda está por vir, não concretizado, em processo; pela sua constituição em retrospectiva, já que faz parte do processo de escritura como pura potência; por ser uma "relação entre eu (ou o Mesmo) e aquilo que interrompe minha própria identidade”. Nas palavras do autor:

\footnotetext{
${ }^{5}$ Em âmbito latino-americano, uma publicação que trabalha com esta denominação é o livro da autora cubana Margarita Mateo Palmer, Ella escribía poscrítica, lançado em pleno "Período especial" cubano, em 1995 e reeditado em 2006. Apesar de explorar procedimentos como o de montagem e ainda contaminar o discurso acadêmico com ficção autobiográfica, ou seja, criar a indeterminação entre crítica e ficção, própria como diz Raúl Antelo da pós-crítica, a publicação volta-se para uma discussão mais próxima aos estudos feministas e ao pós-colonialismo, levantando questões como a proveniência de centros hegemônicos do discurso pós-moderno.

${ }^{6}$ O Colóquio foi realizado em 2006, na Universidade Federal de Santa Catarina, o qual contou com a presença de professores da Universidade de Leiden (Holanda), devido ao convênio e cooperação estabelecido entre as duas universidades. Anterior a este evento é o outro convênio de Cooperação Internacional estabelecido entre a UFSC e a Universidade de Sevilha, em 2004, que resultou, entre outras atividades, na publicação de duas coletâneas de pesquisadores das duas instituições, em torno das relações entre crítica e ficção: Crítica e ficção (2005) e Crítica e ficção, ainda (2006).
} 
A pós-crítica seria, portanto, a tentativa de atender, cabalmente, a duas solicitações simultâneas, porém, suficientemente diversificadas: tanto à alteridade, quanto à singularidade do outro (enquanto outro em relação a mim), sempre em um tempo e um lugar determinados, aos quais o ato crítico tenta responder, com criatividade, para transformar, justamente, a proverbial relação entre o Mesmo e o Outro. (ANTELO, CAMARGO, 2007, p. 8)

Desse modo, os lugares antes fixados - como o do leitor, que segundo a tradição kantiana era quem constituía uma "estética da apreciação" já que era a partir do apreciador, do seu julgamento subjetivo (com pretensão de universalidade), que surgiam os elementos que configurariam a noção de "belo"; ou da obra e do autor que dentro de um modelo teleológico, (presente na teoria hegeliana), constituiria um cânone, um conjunto de obra e/ou nomes válidos que representariam o que há de bom em arte, em literatura - são reconsiderados (ou desconsiderados) e problematizados enquanto “outro", já que não são vistos como totalidades, como prontos e representados no processo de produção da crítica. Na medida em que este "outro" da crítica se constitui no processo crítico, sem se abrir mão de sua singularidade, mas ao mesmo tempo considerando o que faz interrompê-la, ou seja, na medida em que a relação não é a de um sujeito objetivamente definido (a crítica) que lê um objeto completo e acabado também objetivamente (a literatura) - daí a importância da perspectiva serial - se anula ou torna-se impossível um julgamento de valor, a opção por polos antagônicos de avaliação. A crítica abandona normas e regras inclusive a de dever ser crítica. Nem crítica, nem criação são autônomos, trata-se, para Raúl Antelo, de uma dinâmica de forças:

\begin{abstract}
Sob o ponto de vista pós-crítico, na medida em que toda força mantém uma relação essencial com outras forças, a força é intrinsecamente plural. Não faz sentido, em conseqüência, pensá-la em singular, como obra prima ou cânon insuperável: a força é sempre uma relação entre forças, portanto, uma pluralidade. Essa pluralidade, enfim, faz com que toda força sempre seja afetada por outras, daí que a vontade de poder, o desejo de cada força de se tornar objeto exclusivo de atenção para si própria, possa ser traduzido como a intenção ambivalente de poder ser afetado e, ao mesmo tempo, afetar outras forças. (ANTELO, 2002, p. 152-153)
\end{abstract}

Desse modo, cabe perguntar se sua prática entre crítica e ficção já não é em si mesma uma ampliação no sentido de transformação de elementos próprios do literário como a crítica. Ou melhor dizendo, seria possível perguntar se a substituição da relação de certa oposição que a crítica mantinha com a literatura, (enquanto sua abordagem, enquanto objeto a ser observado) pela "pós-crítica", não estaria promovendo uma ampliação do campo no sentido de sua completa transformação. No caso da escrita de Paraná, não se está partindo de um 
objeto fixo a ser examinado mas também de um processo de criação na medida em que se lê; é um exercício crítico, se pensarmos desde a crítica, mas muito além de produzir sentidos em torno do objeto sobre o qual se debruça, propõe um método de leitura (como fica evidente na última parte do livro/texto); e seu propósito "falar de escritores nascidos no Paraná" que a princípio poderia configurar como um propósito crítico/teórico, termina, no entanto, sendo, como afirma o autor, um exercício em torno do topônimo através do qual temporiza-se sobre o espaço. Por outro lado, é um texto que se configura desde o presente, mas não especialmente desde obras e autores literários e contemporâneos.

Ainda em o Indicionario do contemporâneo (2018), obra que propõe na contemporaneidade a discutir e não tanto dar definições categóricas sobre questões atuais em debate na área, o verbete correspondente à pós-autonomia corrobora a importância da leitura, dos modos de ler provocados pela indisciplina contemporânea da literatura:

Poderíamos nos perguntar, ainda, se o que essas escritas do presente estão fazendo não é justamente trazer para a superfície do texto uma indisciplina da literatura que sempre existiu, tornando mais visível o que ela tem de indomesticável e direcionando nosso olhar para aqueles espaços que foram pontos cegos da crítica moderna (e autonômica). (2018, p. 174)

Tal conclusão, que indica a importância da produção contemporânea na condução de uma leitura antes não elaborada e que conclui ser a pós-autonomia para os estudos literários uma reformulação da leitura que pode ser estendida às obras do passado, é imediatamente aqui relacionada ao posicionamento de Raúl Antelo frente a este debate:

Essa é a perspectiva adotada, por exemplo, por Raúl Antelo, que retorna às vanguardas dos anos de 1920 para apontar ali elementos cuja singularidade passou despercebido da crítica, porque "não tínhamos categorias para analisá-las e, consequentemente, avaliá-las". (2018, p. 175)

Resta ainda, portanto, sinalizar a possibilidade de que o método paranoico crítico, enquanto método indisciplinado ou inespecífico de leitura estaria em Raúl Antelo praticando o que a literatura comparada, em uma perspectiva autonômica, descartou ou não leu. Inclusive a leitura em série desencadeada por tal método, é regida, como destaca Daniel Link via Raúl Antelo (2002, p. 26) pelo acaso e coação e não é submissa à sistemas classificatórios e agrupadora de elementos heterogêneos. Neste sentido, em muito dialoga com a literatura comparada em campo expandido proposta por Garramuño que marginaliza uma perspectiva 
de abordagem por diferenças e semelhanças em detrimento de uma abordagem por associações, por trânsitos de fluxos e propostas de conexões, ou seja, modos em que não se partem de elementos já dados e nos quais a importância surge especialmente na possibilidade da série, na possibilidade de estabelecimento da associação.

Sobre a série, vale lembrar as considerações de Walter Benjamin em torno do alegorista e do colecionador. Admirador da figura do colecionador que povoa suas "passagens" parisienses, Benjamin demonstra o quanto a figura do colecionador ou a coleção propriamente dita é ambivalente com relação ao ato de acumular. Para tanto, coloca ao lado do colecionador outra figura: a do alegorista que guarda na importância da figura/imagem o movimento da série:

O alegorista é por assim dizer o pólo oposto ao colecionador. Ele desistiu de elucidar as coisas através da pesquisa do que lhes é afim e do que lhes é próprio. Ele as desliga de seu contexto e desde o princípio confia na sua meditação para elucidar seu significado. O colecionador, ao contrário, reúne as coisas que são afins; consegue, deste modo, informar a respeito das coisas através de suas afinidades ou de sua sucessão no tempo. No entanto - e isto é mais importante que todas as diferenças que possa haver entre eles -, em cada colecionador esconde-se um alegorista e em cada alegorista, um colecionador. No que se refere ao colecionador, sua coleção nunca está completa; e se falta uma única peça, tudo o que colecionou não passará de uma obra fragmentária, tal como são as coisas desde o princípio para a alegoria. Por outro lado, justamente o alegorista, pra quem as coisas representam apenas verbetes de um dicionário secreto, que revelará seus significados ao iniciado, nunca terá acumulado coisas suficientes, sendo que uma delas pode tanto menos substituir a outra que nenhuma reflexão permite prever o significado que a meditação pode reivindicar para cada uma delas. (BENJAMIN, 2006, p. 245)

O colecionador e o alegorista se opõem pelo caráter totalitário da forma com que trabalha o primeiro ou ainda pelo modo como se relacionam com o tempo das coisas com que trabalham: distanciamento, no caso do alegorista, e conservação no caso do colecionador. Mas ambos se imbricam no prazer pelo acúmulo de fragmentos que os colocam diante de desafios abismais, impossíveis: o de ver o fim, a completude e o de reunir mais e mais, já que sempre há algo mais por vir. O mais importante, no entanto, é que o alegorista não está mais preocupado com a completa relação que se estabelece entre aquilo que coleta, porque se distancia das informações dadas previamente e fará gerar o sentido, ou o próprio objeto, no pleno estabelecimento da série. 
Assim sendo, como um último exemplo, em uma parte que se inicia pela palavra "Numância" (ANTELO, 2017, p.15) que remete ao último lugar de resistência à invasão romana na Península Ibérica, Antelo vai tratar de outro autor, nascido no Paraná, um autor contemporâneo: Héctor Schmucler. Schumucler fala em entrevista sobre a memória, conforme Antelo, sobre o fato de que devemos tratar do que aconteceu perguntando sobre o motivo de ter acontecido daquele jeito e não de outro. A essa pergunta se alia um fragmento de Ricardo Zelarayán, que conforme Antelo (ou o narrador que articula a série), também conteria uma pergunta difícil. O fragmento, por sua vez, entre outras coisas, discorre sobre a palavra cinza, em uma canção de Wilson Simonal. É com essa mesma palavra que se inicia o próximo fragmento: “A cinza atiça a "Confissão de um guarda-chuva” (ANTELO, 2017, p. 17) e nele aparece outro escritor, nascido a apenas $200 \mathrm{~km}$ do Paraná argentino e que escreveu O vento que arrasa: Selva Almada. O fim do livro de Almada também trata da chuva e antes que se apresente uma passagem do livro descrevendo uma chuva torrencial, tem-se a afirmação: "Quase no fim dele [do livro de Almada], a sempre presente, a chuva, em outras palavras, o rio: o Paraná.” (2017, p. 17)

A sequência do livro Paraná estabelecida no início deste fragmento pela introdução de mais um autor nascido no Paraná, termina com uma referência ao rio de mesmo nome. Referência essa apenas possível porque esse está tratando da chuva em um livro de um outro escritor nascido no Paraná, e de um livro traduzido por um brasileiro, é importante acrescentar. Pois, o que conecta este livro, este autor ao anterior a ele é justamente a palavra portuguesa "cinza" presente em uma canção de Wilson Simonal e sobre a qual se debruça Ricardo Zelarayán, que é quem está relacionado com Hector Schumucler, o primeiro autor a ser tratado no fragmento e que, lembre-se, nos chama a atenção para que demos mais importância à forma como aconteceu tal fato, do que propriamente ao que aconteceu. Ainda que esteja estabelecida através do corte e recorte e das associações entre os fragmentos uma ficção em torno do que pode ser o Paraná, da mesma maneira, a mesma ficção não deixa de reforçar a presença ali do desenho do próprio método de leitura. Vale salientar aqui também o quanto através deste mecanismo se elimina a possibilidade também de, ao se colocar em diálogo, autores de diferentes países, tratá-los, como nos fala Garramuño em sua proposta de literatura comparada em campo expandido, como unidades fechadas em si mesmo. 
Para terminar, volta-se a salientar que os muitos estudos que se debruçam sobre a noção de campo expandido para pensar a literatura contemporânea se limitam a textos literários, como nos referimos no início desse estudo, que promovem experimentação com a escrita ou nos quais ocorre uma desestabilização do literário gerada, especialmente, pela concomitância de técnicas, suportes e procedimentos de outras artes ou áreas de conhecimento. Mas é importante considerar que os modos com os quais a crítica pratica a leitura na contemporaneidade também diz muito sobre a literatura. Borges considera em texto da década de 50, como nos lembra Daniel Link, que "uma literatura difere da outra, ulterior ou anterior, menos pelo texto que pela maneira de ser lida" (BORGES apud LINK, 2005, p. 192) Assim sendo, propõe-se aqui pensar que em Paraná de Raúl Antelo a proposta concentra-se na articulação de uma leitura em expansão ao sobrepor métodos artísticos e de leitura; e ao tornar indiscernível crítica e ficção. Mas também ao fugir das convenções e estabilizações, como a de que mesmo o elemento espacial, tão tradicionalmente demarcador e definidor, pode ser, ao mesmo tempo, móvel e neutro.

\section{REFERÊNCIAS}

ANTELO, Raúl. Paraná. Curitiba: Editora Medusa, 2017. Coleção Américas Transitivas. - CAMArgo, Maria Lúcia de Barros. (Orgs.) Prefácio. In: Pós-crítica. Florianópolis: Letras Contemporâneas, 2007, p. 7-9.

. Valor e pós-crítica. In: MARQUES, Reinaldo. VILELA, Lúcia Helena. (Orgs.) Valores: arte, mercado, política. Belo Horizonte: UFMG, 2002, p. 152-153.

BENJAMIN, Walter. O colecionador. In: Passagens. (Org.: Wille Bolle) Belo Horizonte: UFMG/São Paulo: IMESP, 2006, p. 245.

DALI, Salvador. El mito trágico del “Angelus” de Millet. Trad. Joan Vinolly. Barcelona: Tusquets, 1978.

FER, Briony. Et. Al. Surrealismo, mito e psicanálise. In: Realismo, racionalismo, surrealismo: a arte no entre-guerras. Trad. Cristina Fino. São Paulo: Cosac NaifY, 1998, p. 171-249.

GARRAMUÑO, Florencia. Frutos estranhos: sobre a inespecificidade na estética contemporânea. Rio de Janeiro: Rocco, 2014.

. La literatura en un campo expansivo y la indisciplina del comparatismo.

Cadernos de estudos culturais. Campo Grande, 2009, p. 101 - 111.

KRAUS, Rosalind. A escultura no campo ampliado. Disponível em: https://monoskop.org/images/b/bc/Krauss_Rosalind_1979 2008 A escultura no campo am pliado.pdf. Acesso em: 29 de maio de 2018 . 
LINK, Daniel. Como se lê e outras intervenções críticas. Trad. Jorge Wolf. Chapecó: Argos, 2002.

Crítica acéfala. Boletim de Pesquisa - NELIC V. 8, No 12 / 13, 2008.

Resenha.

LUDMER, Josefina. Aqui América Latina: una especulación. Buenos Aires: Eterna Cadencia, 2010.

PEDROSA, Celia. KLINGER, Diana. WOLF, Jorge. CÁMARA, Mario. (Orgs).

Pós-autonomia. In: Indicionário do contemporâneo. Belo Horizonte: Ed. UFMG, 2018, p.165-204.

Recebido em 24/09/2019. Aceito em 09/12/2019. 